2017-08-02

\title{
In situ elemental characterisation of marine microplastics by portable XRF.
}

\author{
Turner, Andrew
}

http://hdl.handle.net/10026.1/9922

10.1016/j.marpolbul.2017.07.045

Marine Pollution Bulletin

Elsevier BV

All content in PEARL is protected by copyright law. Author manuscripts are made available in accordance with publisher policies. Please cite only the published version using the details provided on the item record or document. In the absence of an open licence (e.g. Creative Commons), permissions for further reuse of content should be sought from the publisher or author. 


\title{
In situ elemental characterisation of marine microplastics by portable XRF
}

\author{
Andrew Turner* \\ School of Geography, Earth and Environmental Sciences \\ Plymouth University \\ Drake Circus \\ Plymouth PL4 8AA \\ $U K$
}

*Corresponding author. e-mail: aturner@plymouth.ac.uk

http://dx.doi.org/10.1016/j.marpolbul.2017.07.045

Received 12 June 2017; Received in revised form 18 July 2017; Accepted 19 July $2017 \mathrm{E}$

Online August 22017 


\begin{abstract}
The performance of a portable x-ray fluorescence spectrometer configured in a test stand and coupled to a laptop has been evaluated for the determination of various elements (including $\mathrm{Br}, \mathrm{Cd}, \mathrm{Cl}, \mathrm{Cr}, \mathrm{Cu}, \mathrm{Fe}, \mathrm{Pb}$ and $\mathrm{Zn}$ ) in beached microplastics. Under laboratory conditions, analysis of samples that covered the 3-mm x-ray beam returned concentrations that, on average, were within $20 \%$ of concentrations determined by ICP following acid digestion. Analysis of progressively smaller offcuts (to $<1 \mathrm{~mm}$ ) resulted in corresponding concentrations that were comparable to those determined in original samples but errors and detection limits that progressively increased. When the configuration was deployed in situ with two operators, up to 35 microplastics counted for $60 \mathrm{~s}$ each could be processed per hour. Advantages of immediate measurements include the development of an iterative study strategy, rapid compliance-testing, and identification of specific materials for further characterisation or study in the laboratory.
\end{abstract}

Keywords: portable XRF; microplastics; elemental concentrations; heavy metals; in situ

\title{
1. Introduction
}

In addition to the physical risks posed to marine wildlife through, for example, strangulation and ingestion, plastics may act as a vehicle for both the transport and bioaccumulation of organic and inorganic chemicals (Hirai et al., 2011; Rochman et al., 2014). To this end, field-portable x-ray fluorescence (XRF) spectrometry is 
particularly useful in providing a rapid and non-destructive means of characterising the elemental composition of synthetic polymers. Specifically, XRF may be used to evaluate the degree of chlorination, determine whether brominated flame retardants have been added, identify inorganic pigments and detect the presence of hazardous and restricted metals. In a recent article, we described the use of a portable Niton XRF (XL3t) housed in a laboratory stand and configured in a low density mode for the exsitu analysis of a variety of elements in polymeric litter collected from a number of beaches in south west England (Turner and Solman, 2016). Subsequently, this approach has been employed to characterise beached microplastics $(<5 \mathrm{~mm})$ by using the instrument's small-spot facility in which the $\mathrm{x}$-ray beam is collimated to $3 \mathrm{~mm}$ (Massos and Turner, 2017).

Although portable XRF technology has been designed for handheld use in the field, in situ measurements of microplastics are problematic for two reasons. Firstly, and by definition, microplastics are smaller than the diameter of the source-detector window of the instrument (typically $10 \mathrm{~mm}$ ); emplacement of the window directly over the sample and on a suitably flat and dense surface is, therefore, difficult and risks damaging the window itself. Secondly, being of low density, plastics are relatively poor absorbers of radiation (Piorek, 2004), and this has implications both for the generation and detection of fluorescent x-rays, although fundamental parameters is able to correct for this effect to a large extent, and for operator safety. Regarding the latter, secondary x-rays generated by the sample are of primary concern because Compton scatter is greater than photoelectric absorption in low density materials (Bonzi and Mainardi, 1992). Back scatter can be limited by the use of a collar shield around the nose of the instrument, but this adds weight and reduces manoeuvrability 
and renders emplacement of the window on a small sample even more difficult. Moreover, regardless of the use of a collar, a low density sample that is not flush with the surface below scatters radiation radially, an effect that may evade the attention of the operator but that may represent a hazard if the instrument is configured vertically and with the nose pointing downwards.

To overcome these constraints, Niton (Thermo Scientific) have developed a portable test stand in which the XRF is operated remotely via a laptop while the irradiated sample is shielded by a tungsten-PVC casing. This configuration was recently deployed in situ for the determination of trace elements in coastal macroalgae (Turner et al., 2017) and in the present study is trialled and tested for the direct elemental characterisation of beached microplastics. Specifically, the performance of the Niton XL3t and its small-spot facility is evaluated in the laboratory using polyethylene reference discs and microplastics prepared from previously characterised macroplastics (Turner and Solman, 2016) before being deployed at a local beach known to accumulate significant quantities of plastic waste.

\section{Materials and methods}

\subsection{XRF-test stand configuration}

The present study employed a battery-operated, $1.3 \mathrm{~kg}$ Niton XL3t $950 \mathrm{He}$ GOLDD+ energy-dispersive XRF coupled, nose-upwards, to a Thermo Scientific mobile test stand (PN 430-032) and activated via USB using Niton Data Transfer (NDT) software installed on a Fujitsu laptop. Primary X-rays are generated in the XRF by a miniature tube fitted with an $\mathrm{Ag}$ transmission anode that operates at up to $50 \mathrm{kV}$ of high voltage and $200 \mu \mathrm{A}$ of current, while fluorescent $\mathrm{x}$-rays arising from sample excitation are 
detected with a geometrically optimised large area silicon drift detector (GOLDD). The instrument was operated in a low density 'plastics' mode through a standard-less, fundamental parameters-based alpha coefficient correction model that is capable of simultaneously compensating for a wide variety of geometric and fluorescent effects. This mode is able to detect 18 elements, of which 15 in the atomic mass range from $\mathrm{Cl}$ to $\mathrm{Pb}$ are considered in the present study, and incorporates a thickness correction algorithm down to $50 \mu \mathrm{m}$ that accounts for the limited mass absorption of x-rays by polymers.

Throughout the study, the instrument's small-spot facility was employed. Here, the primary beam is collimated to a diameter of $3 \mathrm{~mm}$ at the window aperture through a tapered, tungsten alloy tube of appropriate distal exit aperture diameter that is aligned over the x-ray tube by a geared shutter mechanism. With the sample illuminated by an LED mounted above the detector, real-time imagery from an adjacent CCD camera coupled with a circular reticule, both projected to the laptop and subsequently archived, allow the operator to accurately position the sample with respect to the beam area.

The test stand consists of a $50 \mathrm{~cm}^{2}$ stainless steel baseplate which clips around and is flush with the nose of the XRF. The base plate, nose and sample are shielded by a $300 \mathrm{~cm}^{3}$ tungsten-PVC casing, with access to the sample chamber gained through a hinged lid that locks in to place when pushed down, and, with the XRF nose pointing upwards, the apparatus is raised to about $30 \mathrm{~cm}$ and supported by four detachable steel legs. Connected to the XRF via serial port, the stand also incorporates a safety 
mechanism that ensures the X-ray source is deactivated when the shield lid is unlocked.

\subsection{Performance testing}

The accuracy and precision of the XRF configured in the stand and employing the small-spot facility were evaluated in the laboratory by repeated analyses of two polyethylene discs of diameter $31 \mathrm{~mm}$ and thickness $13 \mathrm{~mm}$ that had been impregnated with known quantities of various elements (Niton PN 180-554, batch SN PE-071-N, and Niton PN 180-619, LOT\#T-18). The performance and limitations of this configuration were assessed by analysing different sizes of sample prepared from archived macroplastics that had been previously collected from various beaches in south west England (Turner and Solman, 2016). Thus, from six fragments (five polyethylene and one PVC), offcuts of different diameter and mass (down to about 1 $\mathrm{mm}$ and $0.5 \mathrm{mg}$, respectively) were prepared using a stainless steel scalpel, while an isolated, $2 \mathrm{~cm}$ strand of $0.4 \mathrm{~mm}$ thickness was unravelled from a 5-mm-thick section of polyethylene fishing rope (Figure 1).

\subsection{XRF analysis}

Samples were measured for thickness through the flattest (measurement) surface using Allendale digital callipers before being placed on a $20-30 \mathrm{~cm}^{2}, 3.6 \mu \mathrm{m}$ thick polyester (Mylar) film that was suspended above the detector window (Figure 2). Positioning with respect to the collimated beam was accomplished by moving either the sample or the underlying film with reference to the CCD video footage and reticule displayed on the laptop. Once the shield of the stand had been locked, measurements, with appropriate thickness correction, were activated through the 
laptop for successive periods of counting at $50 \mathrm{kV}$ and $40 \mu \mathrm{A}$, for the excitation of all elements, and $20 \mathrm{kV}$ and $100 \mu \mathrm{A}$, to enhance the signal from elements of relatively low $(\lesssim 10 \mathrm{keV})$ fluorescent energy. Spectra were quantified by fundamental parameters to yield elemental concentrations on a dry weight basis (in $\mu \mathrm{g} \mathrm{g}^{-1}$ ) and a counting error of $2 \sigma$ (95\% confidence) that were downloaded to the laptop using the NDT software.

\subsection{Sample digestion and analysis by ICP}

As an independent measure of the elemental content of five of the macroplastic samples described above (four fragments of polyethylene and the section of rope), 50$200 \mathrm{mg}$ offcuts were digested in concentrated $\mathrm{H}_{2} \mathrm{SO}_{4}$ at $300{ }^{\circ} \mathrm{C}$ for $2 \mathrm{~h}$ as described elsewhere (Turner and Solman, 2016). Digests were analysed by inductively coupled plasma-optical emission spectrometry (ICP-OES) using a Thermo Scientific iCAP 7400 that had been calibrated using mixed standards prepared by serial dilution of CPI International standards in $2 \% \mathrm{HNO}_{3}$.

\section{Results and Discussion}

\subsection{XRF performance}

In order to estimate an optimal counting period in terms of element detection and sample throughput, various offcuts of macroplastic were firstly subject to XRF analysis over different time periods (between $20 \mathrm{~s}$ and $340 \mathrm{~s}$ ) but with a fixed and successive 2:1 ratio of counting periods at $50 \mathrm{kV}-40 \mu \mathrm{A}$ and $20 \mathrm{kV}-100 \mu \mathrm{A}$. For all samples and elements, detector-estimated measurement errors $(2 \sigma)$ and resulting detection limits $(=2 \sigma \times 1.5)$ were reduced with increasing counting time. Reductions were most significant within the first $60 \mathrm{~s}$, beyond which there were very few cases 
where the benefits of additional element detection were evident. On this basis, a $60 \mathrm{~s}$ period, comprising $40 \mathrm{~s}$ at $50 \mathrm{kV}-40 \mu \mathrm{A}$ and $20 \mathrm{~s}$ at $20 \mathrm{kV}-100 \mu \mathrm{A}$, was selected as a default counting period time for all microplastics.

Table 1 shows the known (added) concentrations of elements in the two Niton polyethylene discs along with concentrations measured repeatedly $(n=10)$ according to the operating conditions described above and using the instrument's small-spot facility. Mean measured concentrations of elements added to discs PN 180-554 and PN 180-619 were within $10 \%$ of mean certified concentrations (as the error at the $95 \%$ confidence level) with the exception of $\mathrm{Ba}, \mathrm{Cr}$ and $\mathrm{Se}$ in the latter disc (where discrepancies of 15 to $30 \%$ were evident). Precision was always better than $10 \%$ with the exception of $\mathrm{Ba}$ in $\mathrm{PN} 180-619$, and no false positives arose from the analysis of either disc; that is, the XRF did not return a concentration where the element had not been added to the polyethylene.

Table 1: Measured and certified elemental concentrations in the two Niton polyethylene discs. Errors represent the standard deviation arising from 10 repeat analyses (measured values) or the error at the $95 \%$ confidence interval (certified values); na $=$ element not added to the disc, and $\angle \mathrm{LOD}=$ below the detection limit $(<$ $3 \sigma)$.

\begin{tabular}{|c|c|c|c|c|c|c|c|c|c|c|c|c|c|c|c|}
\hline & As & $\mathrm{Ba}$ & $\mathrm{Br}$ & $\mathrm{Cd}$ & $\mathrm{Cl}$ & $\mathrm{Cr}$ & $\mathrm{Cu}$ & $\mathrm{Fe}$ & $\mathrm{Hg}$ & $\mathrm{Ni}$ & $\mathrm{Pb}$ & $\mathrm{Sb}$ & Se & $\mathrm{Ti}$ & $\mathrm{Zn}$ \\
\hline \multicolumn{16}{|l|}{ PN 180-554 } \\
\hline certified & na & na & $495+20$ & $150 \pm 6$ & na & $995+40$ & na & na & $1000+40$ & na & $1002 \pm 40$ & na & na & na & na \\
\hline measured & $<L O D$ & $<L O D$ & $501+26$ & $159+16$ & $<L O D$ & $1038+10$ & $<\mathrm{LOD}$ & $<L O D$ & $913+15$ & $<L O D$ & $967 \pm 26$ & $<\mathrm{LOD}$ & $<L O D$ & $<L O D$ & $<L O D$ \\
\hline \multicolumn{16}{|l|}{ PN 180-619 } \\
\hline certified & $51 \pm 7$ & $704+45$ & na & $292+20$ & na & $106 \pm 10$ & na & na & $101 \pm 10$ & na & $150+12$ & $94 \pm 10$ & $207 \pm 15$ & na & na \\
\hline measured & $48+5$ & $518+49$ & $<L O D$ & $272+14$ & $<L O D$ & $123+5$ & $<L O D$ & $<L O D$ & $102+6$ & $<L O D$ & $150 \pm 8$ & $94+13$ & $238+10$ & $<L O D$ & $<L O D$ \\
\hline
\end{tabular}

Elemental concentrations arising from the XRF analysis of four polyethylene macroplastic fragments and the polyethylene rope are compared with concentrations 
determined by acid-digestion-ICP analysis of equivalent 50-200 mg offcuts in Figure 3. Note that data are not shown for $\mathrm{Cl}, \mathrm{Br}$ and $\mathrm{Hg}$ because of problems in detection by ICP and/or loss of volatile forms during heated sample digestion. The XRF returned false positives for As in two cases where concentrations of $\mathrm{Pb}$ were sufficiently high to cause spectral overlap (As-K $\alpha=10.54 \mathrm{keV} ; \mathrm{Pb}-\mathrm{L} \alpha=10.55 \mathrm{keV}$ ), but where elements were not detected by XRF corresponding concentrations returned by ICP were below the respective detection limits of the XRF in its current configuration. With the exception of As, there was a strong and significant correlation $(r=0.947 ; p$ $<0.001)$ between elemental concentrations detected by both analytical approaches. Linear regression analysis of the data revealed a gradient, $m$ (with $95 \%$ confidence interval $)$, of $1.19 \pm 0.18(p<0.001)$ but an insignificant $y$-intercept $(3.6 \pm 83.0 ; p=$ 0.930). Overall, therefore, the XRF returns concentrations that are about $20 \%$ greater than those derived from digestion, possibly because of the incomplete acid dissolution of some samples, the partial precipitation of certain metal salts as digests cooled, or the heterogeneous distribution of some hydrogeneous precipitates (like Fe oxides) on the surface of the plastics. Despite the discrepancies, a correlation coefficient in excess of 0.9 and a relationship of the form $y=m x$ or $y=x$ suggests that the XL3t in its current configuration could potentially be used on microplastics to meet EPA definitive level data criteria (EPA, 2007).

Figure 4 exemplifies the concentrations of various elements returned by the XRF for successively smaller offcuts of six different macroplastics. In most cases, and for a given plastic, concentrations are not different within the range of counting errors returned by the instrument, but the errors themselves increase with decreasing size of offcut. The latter effect is attributed to a reduction in the number of counts 
(fluorescent X-rays) being returned to the detector from within the reticule as sample area and/or thickness declines. A consequence of increasing error is that detection limits also increase and, therefore, elements eventually evade detection below a critical size. This is evident for $\mathrm{Ba}, \mathrm{Ni}$ and $\mathrm{Zn}$ amongst the data shown in Figure 4 but was also observed for other elements when concentrations were close to the corresponding detection limits. Nevertheless, the results reveal that where elements were detected in macroplastic samples covering the detector window or the entire $\mathrm{x}$ ray beam, most were detected in offcuts of a few $\mathrm{mg}$ in mass and a few $\mathrm{mm}^{2}$ in measurement area. Significantly, the main constraints on this approach being extended to smaller sizes of macroplastic were more of a practical nature. For example, manipulating and emplacing samples below these size limits with tweezers was difficult, as was ensuring the face through which thickness had been measured was orientated towards the detector; vibrations and air flow caused by clip-locking the stand shield also tended to disturb smaller samples, often beyond the boundary of the reticule.

Table 2: Mean elemental concentrations ( \pm one standard deviation) and mean counting errors ( \pm one standard deviation) arising from multiple analyses of a section and single strand of polyethylene rope.

\begin{tabular}{|c|c|c|c|c|c|c|}
\hline & $\mathrm{Cl}$ & $\mathrm{Cr}$ & $\mathrm{Fe}$ & $\mathrm{Ni}$ & $\mathrm{Pb}$ & $\mathrm{Ti}$ \\
\hline \multicolumn{7}{|l|}{ whole section } \\
\hline mean concentration $(n=7)$ & $1170+92$ & $302 \pm 9.7$ & $144 \pm 56$ & $27 \pm 1.1$ & $758+31$ & $31+4.4$ \\
\hline mean counting error $(n=7)$ & $178 \pm 6.0$ & $17 \pm 0.5$ & $38 \pm 2.1$ & $17 \pm 0.9$ & $59 \pm-1.6$ & $21 \pm 2.9$ \\
\hline \multicolumn{7}{|l|}{ single strand } \\
\hline mean concentration $(n=8)$ & $1130+327$ & $232+22$ & $<L O D$ & $<L O D$ & $747 \pm 284$ & $<L O D$ \\
\hline mean counting error $(n=8)$ & $248+42$ & $39+3.6$ & $<L O D$ & $<L O D$ & $159+34$ & $<L O D$ \\
\hline
\end{tabular}


To evaluate instrument performance at a lower sample diameter, a single strand of orange, polyethylene rope of diameter $0.4 \mathrm{~mm}$ and length $2 \mathrm{~cm}$ (mass $=3.2 \mathrm{mg}$ ) was positioned centrally across the detector window and within the reticule and held in place at each end with $\sim 5 \mathrm{~g}$ plastic blocks before being analysed repeatedly and as described above. The results, shown in Table 2, reveal that $\mathrm{Cr}, \mathrm{Cl}$ and $\mathrm{Pb}$ were detected with precisions of up to about $20 \%$ and counting errors of between about $20 \%$ and $40 \%$ of the respective mean concentrations. Analysis of the original rope section of $5 \mathrm{~mm}$-thickness resulted in the detection of additional elements ( $\mathrm{Ti}, \mathrm{Fe}, \mathrm{Ni}$ ) but indicated no false positives arising from the analysis of the single strand. Within the counting errors returned or according to a series of unpaired two-sample $t$-tests, mean concentrations of $\mathrm{Pb}$ and $\mathrm{Cl}$ in the section were not different to those returned by the analysis of the individual strand ( $p=0.98$ and 0.65 , respectively) but the mean concentration of $\mathrm{Cr}$ was about $35 \%$ higher (and $p<0.001$ ) in the former; for all three elements, however, analysis of the rope section provided results that were more precise and with lower counting errors.

\subsection{Deployment of the equipment in situ}

An identical configuration of XRF, test stand and laptop was deployed on two occasions and for periods of about two hours each on the upper sand flats of a local estuarine beach (Saltram; 50.3789, -4.0998). The instrument and stand were placed on level sand or on the top of XRF Pelican storage case while the laptop was set up within and protected by the storage case or stand case and, in accordance with local radiation rules, at a distance of $2 \mathrm{~m}$ from the x-ray source (Figure 5). Microplastics were collected with tweezers from the adjacent strandline and wiped clean and dry using two-ply blue roll before being measured for thickness with digital callipers and 
analysed individually for $60 \mathrm{~s}$ under the conditions described and tested above.

Maximising sample coverage by the collimated x-ray beam required one operator to manipulate the sample and polyester film under the guidance of the second operator and through reference to the reticule projected on the screen of the laptop. With two operators concurrently preparing, positioning and analysing samples, between about 25 and 35 microplastics could be processed in an hour, with a potential range of time limited by the number and life of rechargeable battery packs (about $5 \mathrm{~h}$ for each XRF battery and about 90 min for each laptop battery).

A variety of primary and secondary microplastics $(<5 \mathrm{~mm})$ of different colour were analysed and the results, exemplified for one sampling of Saltram beach in Figure 6, reveal elemental distributions and concentration ranges that are broadly consistent with findings from previous, larger-scale but laboratory-based studies (Turner, 2016; Massos and Turner, 2017). Specifically, there was a relatively low proportion of PVCbased materials and an abundance of $\mathrm{Fe}, \mathrm{Ti}$ and (non-PVC-based) $\mathrm{Cl}$ throughout; $\mathrm{Cd}$ or $\mathrm{Pb}$ were present in many coloured fragments and at concentrations in some cases that exceeded their respective restricted limits for plastics $\left(100 \mu \mathrm{g} \mathrm{g}^{-1}\right.$ and $1000 \mu \mathrm{g} \mathrm{g}^{-1}$ according to the EU Restrictions of Hazardous Substances Directive; RoHS, 2006); $\mathrm{Br}$ was present in many green or neutrally-coloured samples, presumably in the form of phthalocyanine pigments and various brominated flame retardants, respectively (Massos and Turner, 2017); and $\mathrm{Hg}$, Se and, where spectral interference from $\mathrm{Pb}$ could be ruled out, As were detected in isolated incidences.

The general advantages of XRF include minimal operator training, rapid, nondestructive and inexpensive analyses, and avoidance of hazardous waste. Additional 
benefits of performing measurements in situ include the development of a strategy or focus that is directly informed or iterated by immediate results, rapid characterisation of microplastics arising from a spillage and testing for RoHS-compliance, and identification and collection of specific materials for further study in the laboratory. With respect to the latter, contaminant adsorption experiments may rely on a particular type or composition of plastic (Holmes et al., 2014), while bioaccessibility tests may wish to target microplastics that contain harmful and restricted pigments or brominated flame-retardants (Turner and Lau, 2016). The in situ approach is also useful for the rapid screening of offcuts of samples that would otherwise be difficult or time-consuming to retrieve or transport, such as microplastics embedded in oil tar deposits and large, bulky objects or conglomerates.

The main practical difficulty in deploying the equipment in the field was found to be associated with the introduction of contaminants (and mainly sand particles) into the sample chamber, despite attempts to pre-clean samples and tweezers. While the instrument itself is sealed against dust, particulate contaminants on the polyester film may partially obscure the primary $\mathrm{x}$-ray beam and absorb fluorescent $\mathrm{x}$-rays. To minimise contamination, the film was replaced regularly and the steel base-plate and instrument nose were brushed or blown clear when particulates were visible. In situ measurements are also weather-dependent unless the equipment is set up on the interior surfaces of a parked vehicle. Thus, although the instrument and window are moisture-resistant, small drops of water can act like $\mathrm{x}$-ray absorbing contaminants as described above, while gusts of wind may adversely impact on the ability to manipulate small samples and clean, change or secure the polyester film protecting the detector window. 


\section{Conclusions}

The Niton XL3t XRF configured with a small-spot facility and in a mobile test stand is capable of rapidly determining the elemental content of beached microplastics down to sub-mm and sub-mg dimensions and with results that, on average, are within about $20 \%$ of those delivered independently by ICP following acid digestion. While not as sensitive as ICP, the XRF deployed in situ allows a research strategy to be developed iteratively, provides immediate characterisation of samples arising from a spillage, and facilitates in the identification and collection of materials that are required for further experimental study.

\section{Acknowledgements}

Mr Chris Bode and Dr Ken Grainger (Niton, UK) are acknowledged for technical advice, and Mr Chiu Ho, Dr Andrew Fisher, Mr Rupert Goddard and Dr Alex Taylor (UoP) are thanked for practical assistance. This work was funded by a UoP Marine Institute HEIF V grant.

\section{References}

Bonzi, E.V., Mainardi, R.T., 1992. Monte Carlo calculations of efficiencies for photon interactions in plastic scintillators. Nuclear Instruments and Methods in Physics Research, Section B: Beam Interactions with Materials and Atoms 72, $477-$ 480.

Environmental Protection Agency, 2007. Method 6200 - Field portable x-ray fluorescence spectrometry for the determination of elemental concentrations in soil 
and sediment.

http://www3.epa.gov/epawaste/hazard/testmethods/sw846/pdfs/6200.pdf. Accessed $\underline{4 / 17}$.

Hirai, H., Takada, H., Ogata, Y., Yamashita, R., Mizukawa, K., Saha, M., Kwan, C., Moore, C., Gray, H., Laursen, D., Zettler, E.R., Farrington, J.W., Reddy, C.M., Peacock, E.E., Ward, M.W., 2011. Organic micropollutants in marine plastics debris from the open ocean and remote and urban beaches. Marine Pollution Bulletin 62, $1683-1692$.

Holmes, L.A., Turner, A., Thompson, R.C., 2014. Interactions between trace metals and plastic production pellets under estuarine conditions. Marine Chemistry 167, 2532.

Massos, A., Turner, A., 2017. Cadmium, lead and bromine in beached microplastics. Environmental Pollution 227, 139-145.

Piorek, S., 2004. Feasibility of analysis and screening of plastics for heavy metals with portable x-ray fluorescence analyser with miniature x-ray tube, GPEC 2004 Paper abstract \#14.

Rochman, C.M., Hentschel, B.T., Teh, S.J., 2014. Long-term sorption of metals is similar among plastic types: Implications for plastic debris in aquatic environments. PLOS ONE http://dx.doi.org/10.1371/journal.pone.0085433. 
RoHS, 2006. Restriction of Hazardous Substances, EU Directive 2002/95/EC

http://www.rohsguide.com/rohs-substances.htm (accessed April 2017).

Turner, A., 2016. Hazardous metals, metalloids and other elements in marine litter. Marine Pollution Bulletin 111, 136-142.

Turner, A., Holmes, L., 2015. Adsorption of trace metals by microplastic pellets in fresh water. Environmental Chemistry 12, 600-610.

Turner, A., Lau, K., 2016. Elemental concentrations and bioaccessibilities in beached plastic foam litter, with particular reference to lead in polyurethane. Marine Pollution Bulletin 112, 265-270.

Turner, A., Solman, K.R., 2016. Analysis of the elemental composition of marine litter by field-portable-XRF. Talanta 159, 262-271. 

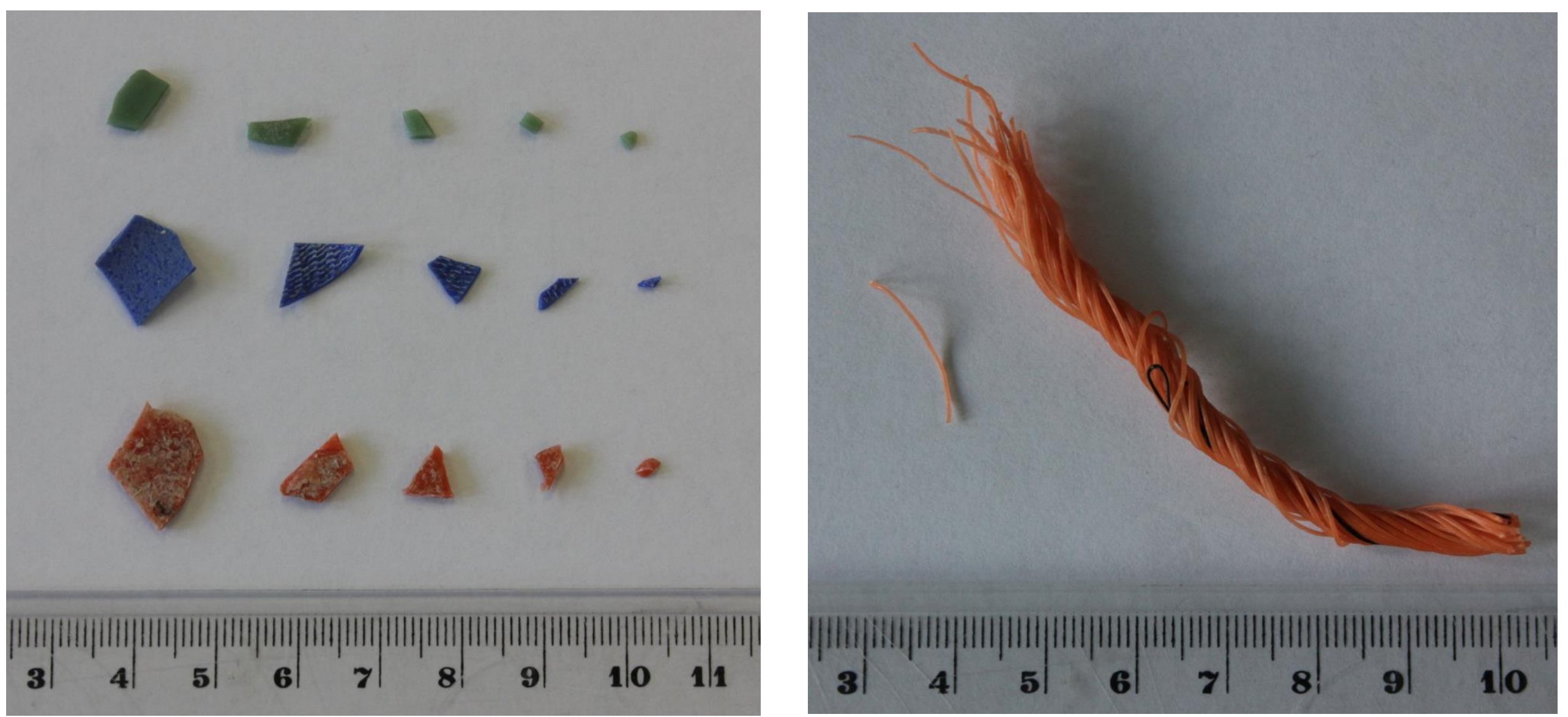
2 Figure 2: (a) An offcut of beached PVC suspended over the $10 \mathrm{~mm}$ detector window of the Niton XL3t and (b) a projected CCD video image of an offcut of beached 3 polyethylene positioned within the $3 \mathrm{~mm}$ reticule.

4

5

(a)

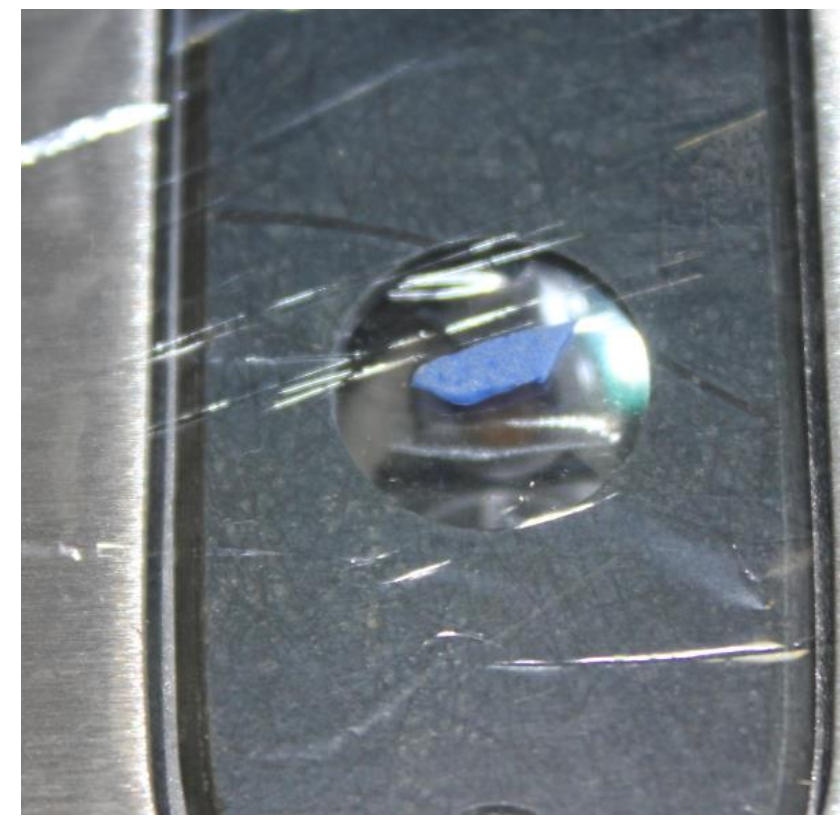

(b)

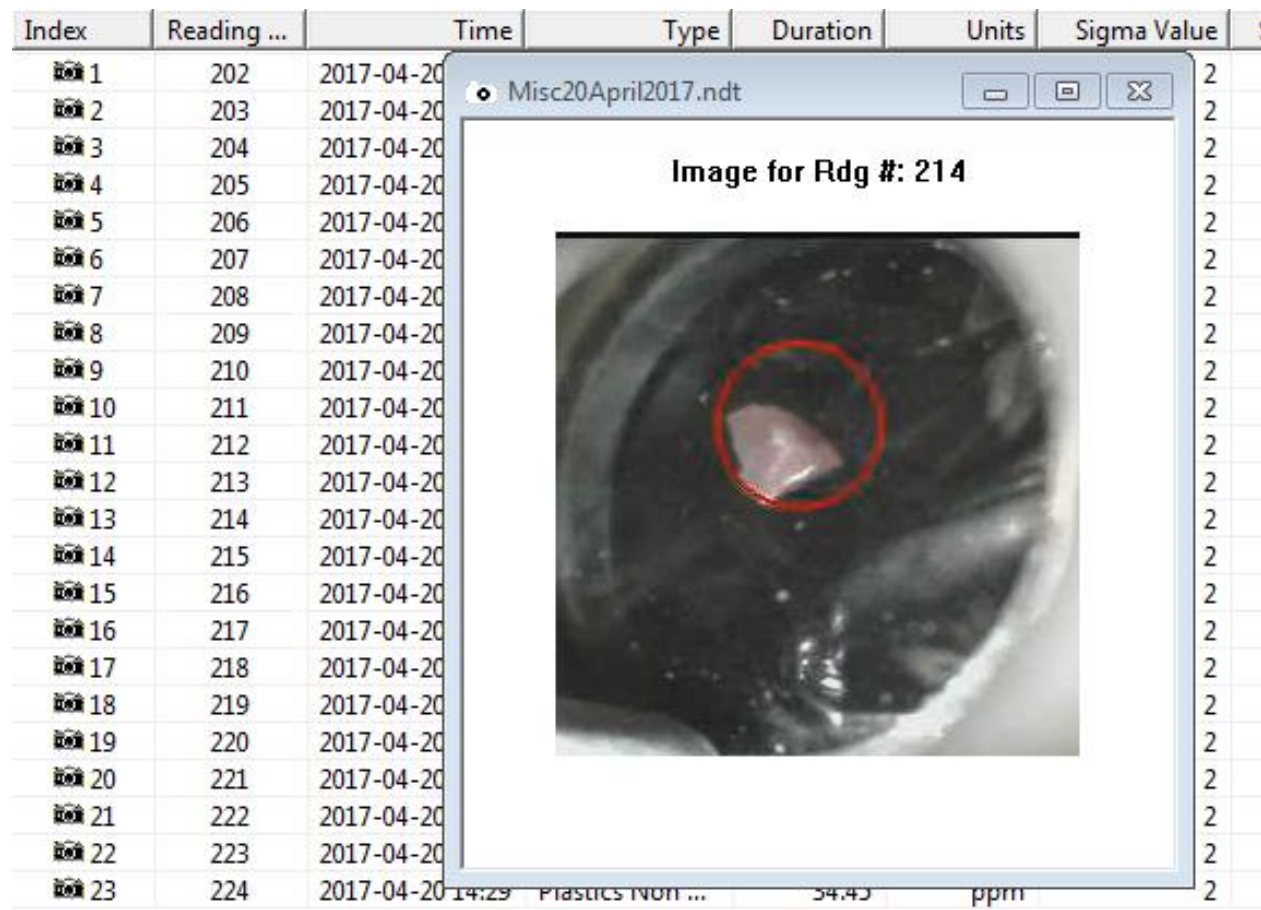



following acid digestion.

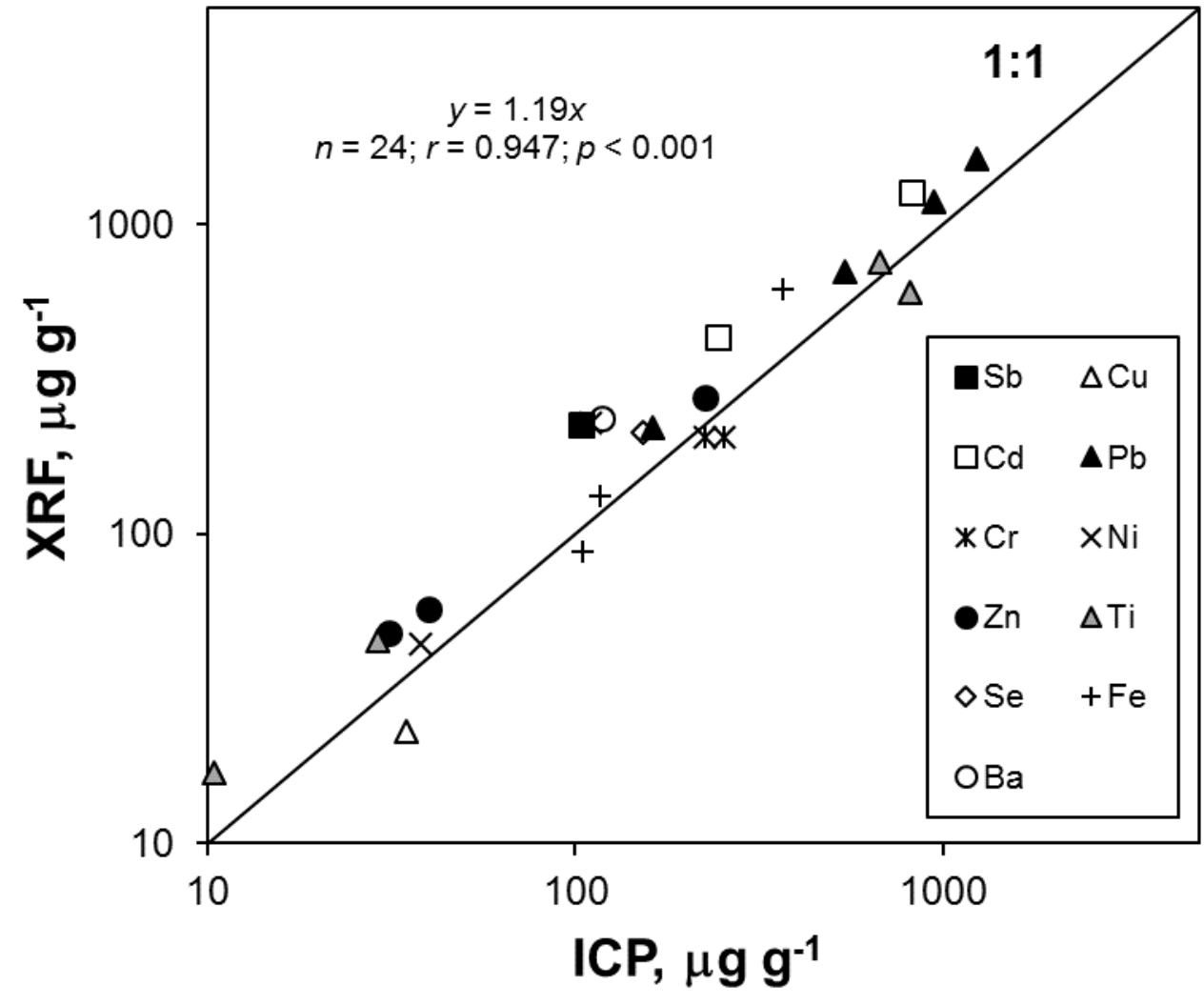


Figure 4: A selection of elemental concentrations arising from the XRF-analysis of different sizes of offcut from six beached macroplastics. Samples are coded in terms of measurements that were below the detection limit of $3 \sigma$.

27
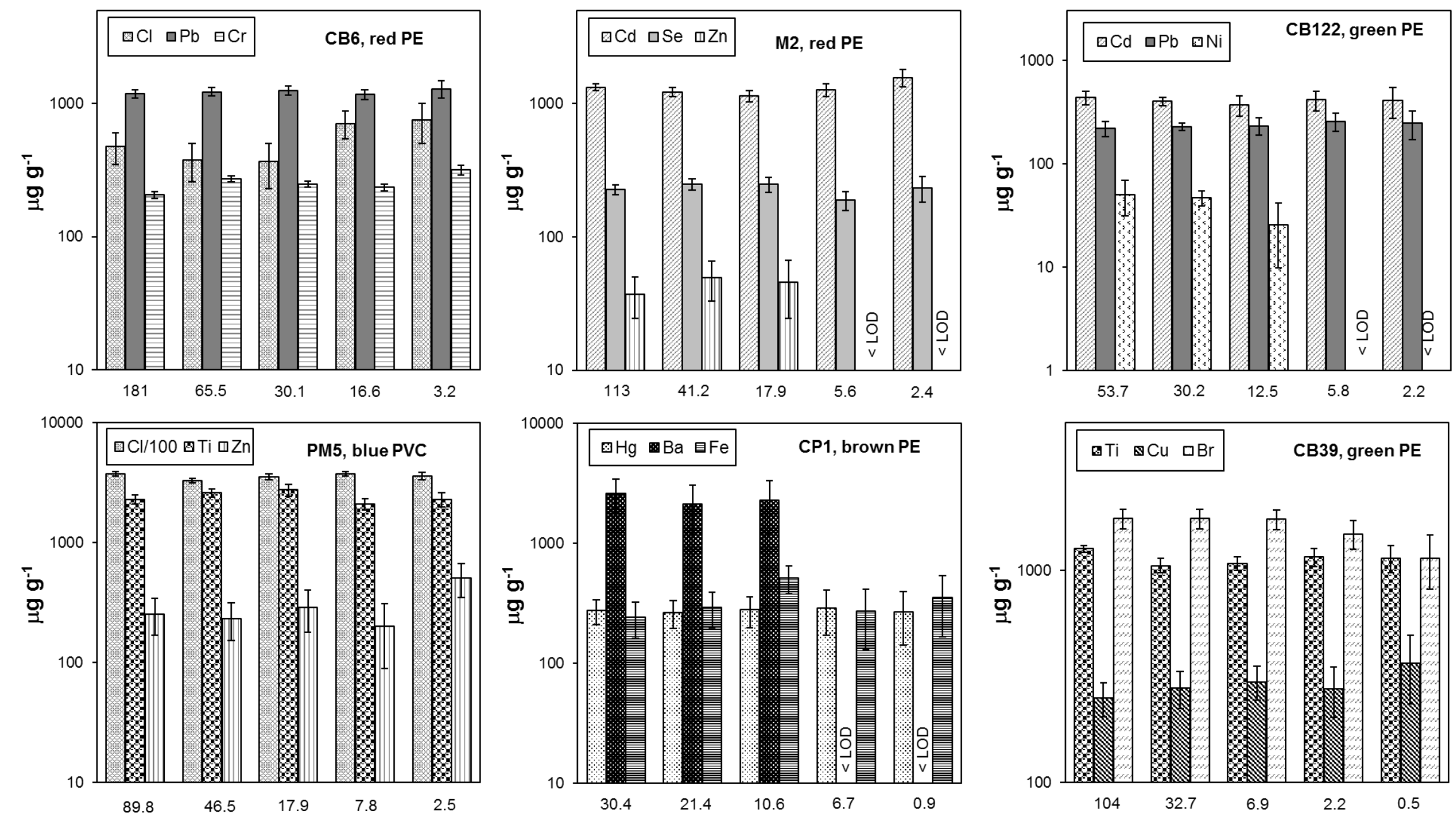
28 Figure 5: Configuration of the Niton XL3t, mobile test stand and laptop in the field.
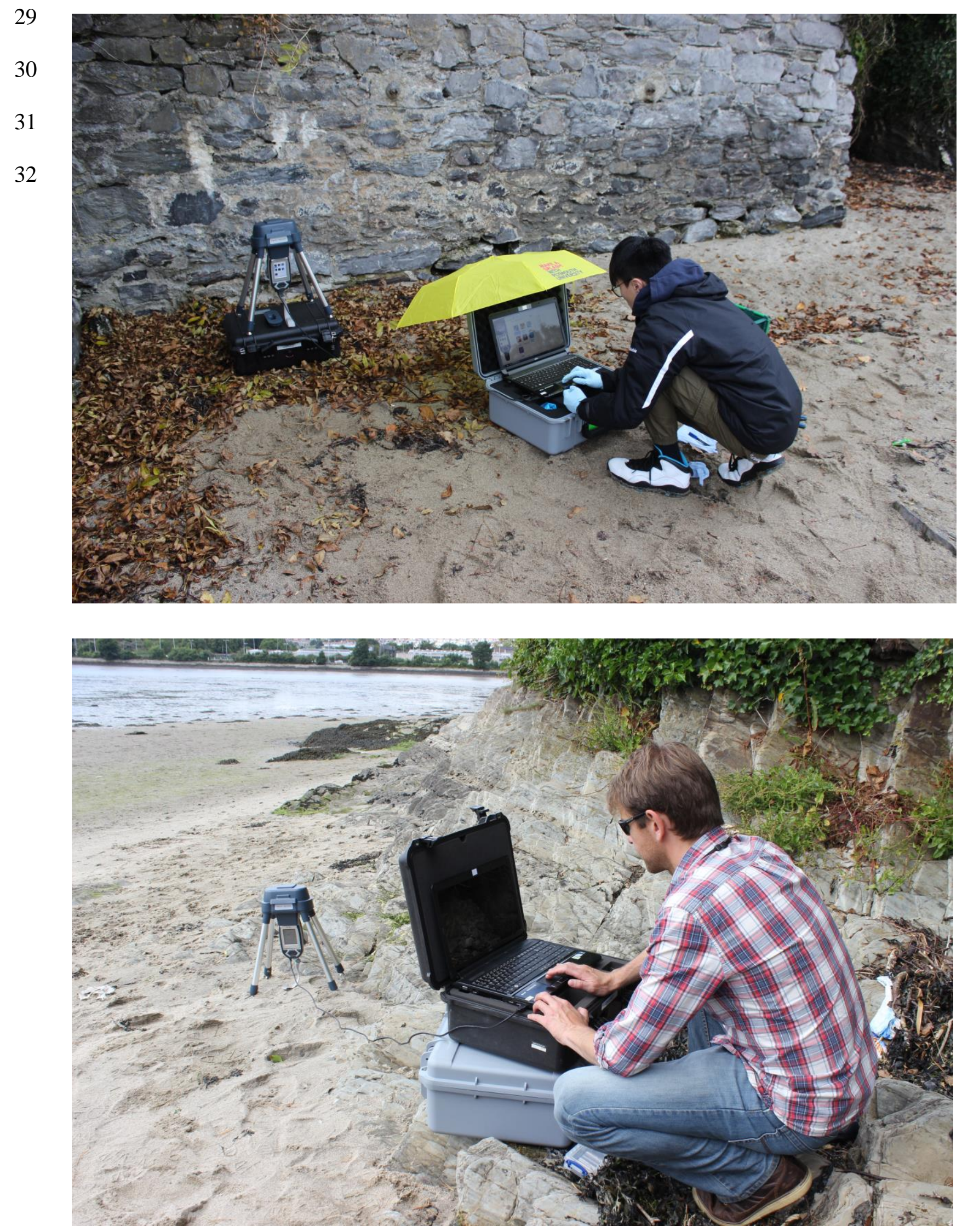
33 Figure 6: Number of cases in which each element was detected by the Niton XL3t

34 among 50 samples tested in situ at Saltram beach. The concentration range (or single

35 concentration; $n=1$ ) returned is given above each data point in $\mu \mathrm{g} \mathrm{g}^{-1}$.

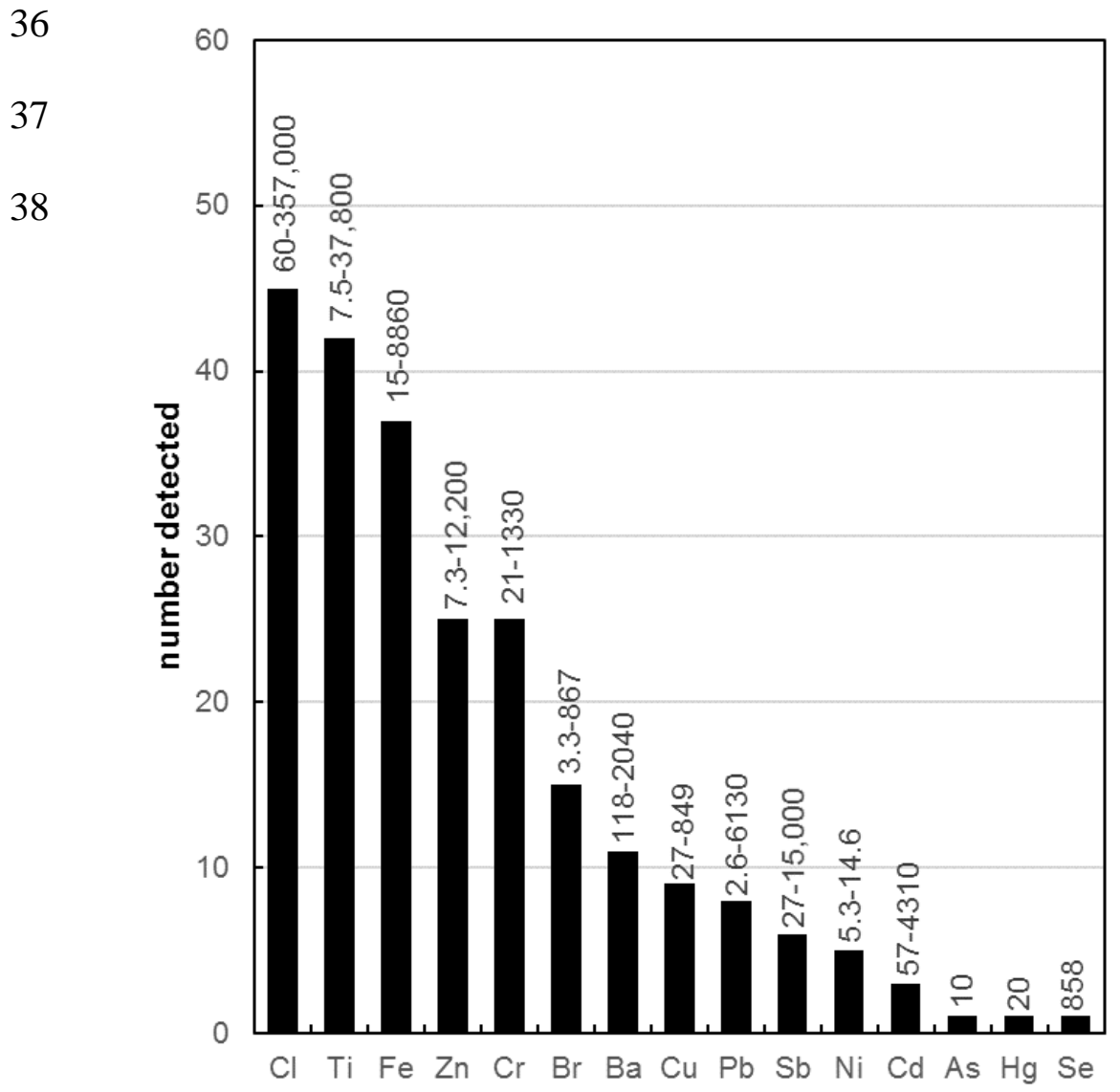

